(2) Open Access Full Text Article

REVIEW

\title{
A meta-analysis of levetiracetam for randomized placebo-controlled trials in patients with refractory epilepsy
}

This article was published in the following Dove Medical Press journal: Neuropsychiatric Disease and Treatment

\section{Daye Chen \\ Hongliang Bian \\ Lanlan Zhang}

Department of Pediatrics, Yancheng Maternal and Child Health Hospital, Yancheng, People's Republic of China

Correspondence: Hongliang Bian Department of Pediatrics, Yancheng Maternal and Child Health Hospital, No 34, Yulong West Road, Yancheng City, Jiangsu, People's Republic of China Tel +86 I34 85207868

Email contribute_sci@I26.com
Objective: The objective of this study was to investigate the efficacy and safety profile of levetiracetam as add-on therapy in patients with refractory epilepsy.

Methods: Web of Science, MEDLINE (Ovid and PubMed), Cochrane Library, EMBASE, and Google Scholar were systematically searched to identify potential eligible randomized controlled trials by two reviewers independently. Pooled estimates of risk ratios (RRs) for $50 \%, 75 \%$, and $100 \%$ reduction from baseline were calculated using the fixed-effect model or random-effect model. Quality of included studies was assessed with the Cochrane Collaboration's Risk of Bias tool. Serious adverse events and withdrawals induced by interventions and the most common side effects were analyzed.

Results: Seventeen trials with a total of 3,205 participants were included in this meta-analysis, including 14 trials for adulthood and three trials for children. Pooled estimates suggested that levetiracetam was an effective anti-epileptic drug at $1,000-3,000 \mathrm{mg} /$ day $(\mathrm{RR}=2.00$ for $1,000 \mathrm{mg} /$ day, $R R=2.68$ for $2,000 \mathrm{mg} /$ day, $R R=2.18$ for $3,000 \mathrm{mg} / \mathrm{day}$ ) for adults and $60 \mathrm{mg} / \mathrm{kg} /$ day $(\mathrm{RR}=2.00)$ for children compared to placebo in terms of $50 \%$ reduction from baseline. Likewise, as for seizure freedom rate, levetiracetam had an advantage over placebo at $1,000-3,000 \mathrm{mg} /$ day $(\mathrm{RR}=5.84$ for $1,000 \mathrm{mg} / \mathrm{day}, \mathrm{RR}=4.55$ for $2,000 \mathrm{mg} / \mathrm{day}, \mathrm{RR}=4.57$ for $3,000 \mathrm{mg} /$ day, respectively) for adults and $60 \mathrm{mg} / \mathrm{kg} /$ day $(\mathrm{RR}=4.52)$ for children. Regarding safety profile, patients treated with levetiracetam had significantly higher occurrence than placebo for somnolence, asthenia, dizziness, infection, nasopharyngitis, anxiety, and irritability; however, most studies reported that these adverse events were mild and transient.

Conclusion: Levetiracetam is an effective anti-epileptic drug for both adults and children with generalized or partial-onset refractory seizures at 1,000-3,000 or $60 \mathrm{mg} / \mathrm{kg} / \mathrm{day}$, with a favorable adverse event profile.

Keywords: levetiracetam, adjunctive, refractory epilepsy, placebo

\section{Introduction}

Epilepsy is a serious neurological disorder, with the prevalence of $\sim 0.5 \%-1 \%$ in developed countries, ${ }^{1}$ and it rises up to $7.4 \%$ in developing countries because of inferior health care and a higher proportion of children. ${ }^{2,3}$ Maintaining seizure freedom by using a tolerated anti-epileptic drug (AED) schedule is the goal of epilepsy treatment. However, of the 50 million people who suffer epilepsy, nearly one third were treated with available AEDs but due to lack of favorable effect, they still have onsets; this is regarded as "drug-resistant" or "refractory."4 Besides, side effects induced by AEDs leading to failed adequate seizure control account for $20 \%-30 \%$ of the patients. ${ }^{5}$ 
As a broad-spectrum AED, levetiracetam ((S)- $\alpha$-ethyl2-oxo-1-pyrrolidine acetamide) has unique mechanisms of action that differs from other AEDs. A study published recently revealed that through binding, levetiracetam modulates the activity of synaptic vesicle protein $2 \mathrm{~A}$ in brain neurons to maintain a normal level, and as a result seizures reduce. ${ }^{6}$ Compared to other AEDs, levetiracetam has a favorable pharmacokinetic profile in both adulthood and childhood. After oral administration, levetiracetam will be rapidly and almost 100\% absorbed in a few hours; the peak serum concentration is achieved in $\sim 1$ hour (0.6-1.3 hours). Mean half-life of levetiracetam is about 6-8 hours in young adulthood and increases to 10-11 hours in elderly patients, and within 24-48 hours, the dose-proportional pharmacokinetic maintains a steady state serum level. One favorable characteristic of levetiracetam is that to date, there are few reports concerning pharmacokinetic drug interactions with levetiracetam in adults and children alike. ${ }^{7,8}$ In comparison with adulthood, body clearance of levetiracetam in childhood is higher of about $30 \%-40 \%$, and therefore, the recommended dose for children is about $130 \%-140 \%$ of that of adulthood, equivalent to $20-60 \mathrm{mg} / \mathrm{kg} / \mathrm{day}$, but should be adjusted according to body weight. ${ }^{9}$ Moreover, studies revealed that the pharmacokinetic profile of single-dose levetiracetam in children aged 2-46 months is similar to those aged $>4$ years, suggesting that levetiracetam could be used in infants and young children. ${ }^{10}$ Since introduced in the market in 2000 , levetiracetam has become first-line and one of the most commonly prescribed AED and is recommended as add-on agent for partial seizures, benign childhood epilepsy with centrotemporal spikes, and myoclonic epilepsy. ${ }^{11}$ This metaanalysis aimed to investigate the effects of levetiracetam as adjunctive therapy for patients suffering from refractory generalized or partial-onset epilepsy.

\section{Materials and methods}

This meta-analysis was performed and reported in accordance with the PRISMA. ${ }^{12}$ Responder rate $(50 \%$ reduction from baseline) and seizure freedom (100\% reduction from baseline) were the primary outcomes for this meta-analysis. Serious adverse events (SAEs) during treatment induced by interventions and premature termination related to interventions were regarded as the secondary outcomes.

\section{Search strategy and selection criteria}

For this systematic review and meta-analysis, following databases were searched from inception up to May 31, 2018: EMBASE, MEDLINE, Web of Science, Cochrane Library PubMed, and Google Scholar, as well as Chinese
National Knowledge Infrastructure and Wanfang Data databases. A combination of relevant keywords, abbreviations, and synonyms for levetiracetam and refractory partial epilepsy are as follows: (levetiracetam) and ([refractory $]$ or [uncontrolled $]$ or [drug-resistant $]$ ) and ([onset $\left.{ }^{*}\right]$ or [seizure*] or [epilepsy]). Database search was supplemented by manual screening of the references of relevant articles and reviews, and there was no restriction on publication language. Two reviewers (Chen and Bian) assessed the eligible articles independently, disagreements were resolved via discussion and, if necessary, arbitrated by the third reviewer (Zhang).

\section{Inclusion criteria}

Studies were included only if they meet all the following criteria: 1) involved refractory epilepsy, regardless of age and gender, 2) must be randomized controlled trials (RCTs) that involved levetiracetam, 3) reported at least one efficacy of responder or seize freedom rate, and 4) detailed adverse events (AEs) including dropouts owing to AEs and SAEs were reported.

\section{Exclusion criteria}

Studies were excluded if they meet any of the following criteria: 1) non-RCT studies such as retrospective and observational studies, 2) compared to other AEDs rather than placebo, 3) not for refractory epilepsy but other diseases such as migraine or autism, 4) not reported detailed efficacy of responder and/or seizure freedom and adverse profile, and 5) conference abstracts, guidelines, editorials, letters, and reviews.

\section{Data extraction and quality evaluation}

To standardize the data extraction process, we developed a data collection form with Excel (Office 2013; Microsoft Corporation, Redmond, WA, USA), and following data were extracted from each study: 1) study and demographic characteristics: first author, year of publication, country, sample size, patient age, and ratio of male/female and 2) clinical characteristics: dosage, follow-up period, responder and seizure freedom number, total number of AEs, premature termination owing to AEs, SAEs, and specific side effects reported by more than three trials. Risk of bias for included studies was evaluated with the Cochrane Collaboration's Risk of Bias tool, which covered seven aspects of random sequence generation, allocation concealment, blinding of outcome participants and personnel, blinding of outcome assessment, incomplete outcome data, selective reporting, and other bias. Each RCT was regarded as high, low, or unclear risk 
of bias for these aspects. Quality assessment was performed by two reviewers (Chen and Bian) independently; in case of disagreements, the third reviewer (Zhang) was consulted.

\section{Data synthesis and analysis}

Outcomes were reported as risk ratio (RR) with $95 \% \mathrm{CI}$, with fixed-effect model if there was no significant heterogeneity identified, ${ }^{13}$ otherwise the random-effect model was used to calculate. ${ }^{14}$ Heterogeneity across studies was assessed by Cochran's $Q$ test and measured with inconsistency index $\left(I^{2}\right)$, value of which was interpreted as follows: 1) $0 \%-40 \%$ was considered as not important, 2) $30 \%-60 \%$ was considered as moderate, 3) $50 \%-90 \%$ was considered as substantial, and 4) $75 \%-100 \%$ was regarded as considerable. ${ }^{15} \mathrm{~A}$ funnel plot was presented to visually evaluate the publication bias, quantified by Egger regression and Begg-Mazumdar test. ${ }^{16,17}$ All randomized participants were analyzed based on intention-totreat patient population, namely in the treatment group they had been allocated, irrespective of the treatment that they actually received. Participants randomized but excluded from analysis were assumed non-responders. If the difference in dosage between studies was slight, then for sake of convenient calculation, we categorize them in the same group; in this case, we would make a specific declaration. Subgroup analyses based on dosage and age were performed as well. A $P$-value $<0.05$ was regarded as statistically significant. Pooled estimates of RRs and corresponding 95\% CIs of 50\%, $75 \%$, and $100 \%$ of seizure reduction from baseline, along with SAEs and dropout due to interventions, were presented in the forest plots. Another measurement for epilepsy treatment is quality of life (QoL), but to date widely accepted instruments to assess it are still lacking; therefore, we did not combine the results of QoL. All analyses were performed with the STATA 14.1 (Stata Corporation, College Station, TX, USA) and the "metan" module of it.

\section{Results}

\section{Literature search}

Figure 1 describes an overview of the study selection process. The initial systematic search yielded 1,325 results, of which

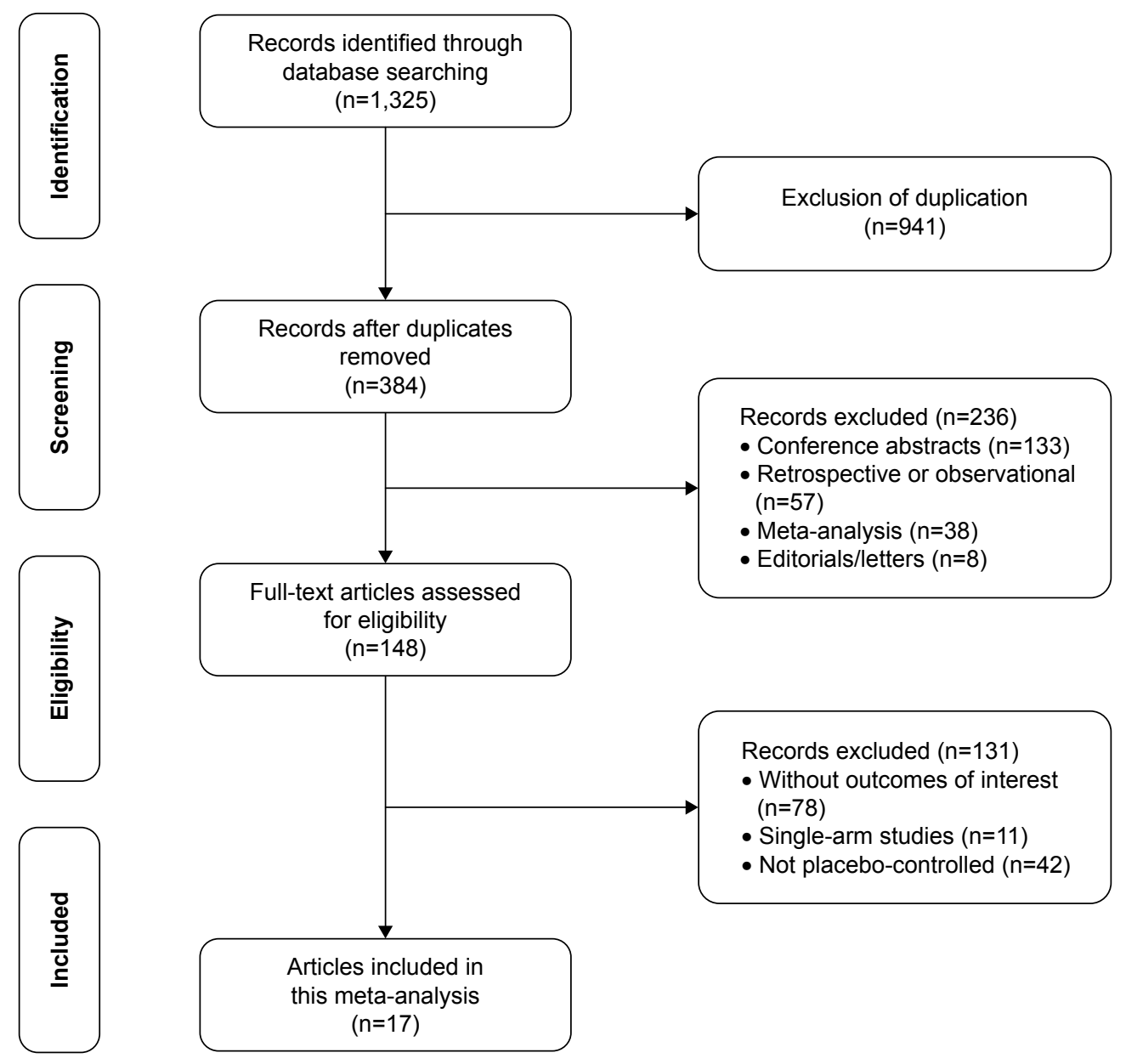

Figure I Study selection process for this meta-analysis. 
975 were removed for duplicates. Of the remaining 384 articles, 138 were excluded for conference abstracts, 57 for retrospective or observational studies, and 38 for systematic reviews or meta-analyses. Full-text screening was performed by two reviewers independently and manually, then 128 articles were ruled out for following reasons: 75 studies did not report sufficient data for efficacy or AEs; 11 studies were single-arm trials, and 42 studies were compared to other AEDs such as oxcarbazepine, sulthiame, or carbamazepine rather than placebo. Eventually, a total of 17 RCTs with 3,205 participants were included in the current meta-analysis. , $, 5,10,18-30^{-30}$

\section{Study characteristics}

Details of demographic and clinical characteristics for 17 RCTs are summarized in Table 1. Sample size for these trials ranged from 24 to 351 . Fourteen trials involved adult patients ${ }^{2,5,18-25,27,31}$ and three involved children, ${ }^{10,26,28}$ with age ranging from 1 month to 69 years. Regarding the 14 trials involving adults, the most administered dosages were 1,000, 2,000, and 3,000 mg/day. However, in the trial of Inoue et al, single-arm participants were administered at $500 \mathrm{mg} /$ day ${ }^{27}$ Another exception was in the trial of Betts et al, in which dosage reached 4,000 mg/day. ${ }^{5}$ Of the three trials involving children, two used the maximum dosage of $60 \mathrm{mg} / \mathrm{kg} / \mathrm{day},{ }^{26,28}$ the remaining one used slightly less, at a maximum of $50 \mathrm{mg} / \mathrm{kg} /$ day. ${ }^{27}$ In nearly all the included trials, levetiracetam was administered orally twice-daily; the only exception was trial of Peltola et al, in which levetiracetam was administered $1,000 \mathrm{mg} /$ day once daily. ${ }^{18}$ Most of the trials lasted at least 16 weeks; however, the trial of Piña-Garza et al only lasted 7 days, which may bring about potential risk of bias for outcomes. ${ }^{10}$ Of the 17 RCTs, 15 involved patients with refractory partial-onset seizures, whereas the two others were designed to assess the efficacy for patients with uncontrolled idiopathic generalized epilepsy. ${ }^{29,30}$

\section{Quality assessment of included studies}

Details of risk of bias for each RCT are presented in Figure 2. Ten trials were considered as low risk of bias, because sequence generation and allocation method were described. ${ }^{2,5,18-21,25,26,29,30}$ The remaining seven trials were regarded as risk of selection bias, mainly because insufficient information for random list generation and allocation concealment were not reported. ${ }^{10,22-24,27,28,31}$ All trials were reported to be double-blind trials; however, six trials did not describe the details of approaches applied to blind participants and personnel, then regarded as unclear for risk of bias. ${ }^{19,27-31}$ Most of the trials were viewed as low risk of bias concerning incomplete outcome data biases; nevertheless, three trials were considered as high risk of bias, for the number of patients reported after treatment was not consistent with the initial number. ${ }^{5,10,31}$ In general, the quality assessment for all included RCTs was not very high.

\section{$50 \%$ reduction from baseline}

$50 \%$ reduction from baseline was reported by all RCTs. Pooled estimates suggested that patients treated with levetiracetam had substantial higher responder rate than those with placebo $(\mathrm{RR}=2.17,95 \%$ CI 1.93-2.43, $P<0.05)$, and heterogeneity test showed that there was no significant different $\left(I^{2}=12.9 \%, P=0.28\right)$. Subgroup analysis based on dosage showed that pooled estimates from five trials at $2,000 \mathrm{mg} /$ day possessed the optimal efficacy of the responders $(\mathrm{RR}=2.68$, 95\% CI 1.99-3.61), ${ }^{2,5,19,21,27}$ and for other dosages of 1,000, 3,000 , and $60 \mathrm{mg} / \mathrm{kg} / \mathrm{day}$, they had comparable efficacy $(\mathrm{RR}=2.00$ with $95 \% \mathrm{CI} 1.56-2.57$; RR $=2.18$ with $95 \% \mathrm{CI}$ 1.84-2.58; and RR $=2.00$ with 95\% CI 1.50-2.67, respectively). Moreover, results suggested that regarding these four dosages, levetiracetam had a considerable advantage over placebo $(P<0.05)$. One trial involved a dosage of $500 \mathrm{mg} /$ day and one involved 4,000 mg/day, and the results suggested that the efficacy was not as good as the other dosages $(\mathrm{RR}=1.63$, 95\% CI 0.72-3.68, $P=0.24$ and $\mathrm{RR}=1.64,95 \% \mathrm{CI} 0.59-4.57$, $P=0.34)$. Subgroup analysis based on age $(<16$ years vs $>16$ years) showed that adult patients treated with levetiracetam had a slightly better efficacy of responder rate than children $(\mathrm{RR}=2.08,95 \% \mathrm{CI} 1.83-2.34$ and $\mathrm{RR}=1.94,95 \%$ CI 1.46-2.57). Subgroup analysis according to epilepsy type (generalized vs partial) showed that levetiracetam had a better efficacy of responder rate in patients with partial epilepsy (for partial-onset, $\mathrm{RR}=2.14$, and for generalized epilepsy, $\mathrm{RR}=1.75)$. However, there was no statistically significant difference between them $(P=0.14)$. Figure 3 presents the details of responder rate based on dosage.

\section{Seizure freedom from baseline}

All RCTs reported details regarding seizure freedom within the treatment period, and pooled estimates demonstrated that levetiracetam behaved considerably better than placebo overall ( $\mathrm{RR}=4.68,95 \%$ CI 3.19-6.85). According to subgroup analysis, dosage of $1,000 \mathrm{mg} /$ day had the best efficacy compared to placebo $(\mathrm{RR}=5.84,95 \%$ CI 2.28-14.97, $P<0.05$ ), followed by the dosages of $2,000,3,000$, and $60 \mathrm{mg} /$ $\mathrm{kg}$ /day with minute difference among these three doses $(\mathrm{RR}=4.55,95 \% \mathrm{CI} 1.75-11.87 ; \mathrm{RR}=4.57,95 \% \mathrm{CI} 2.50-8.35$; 


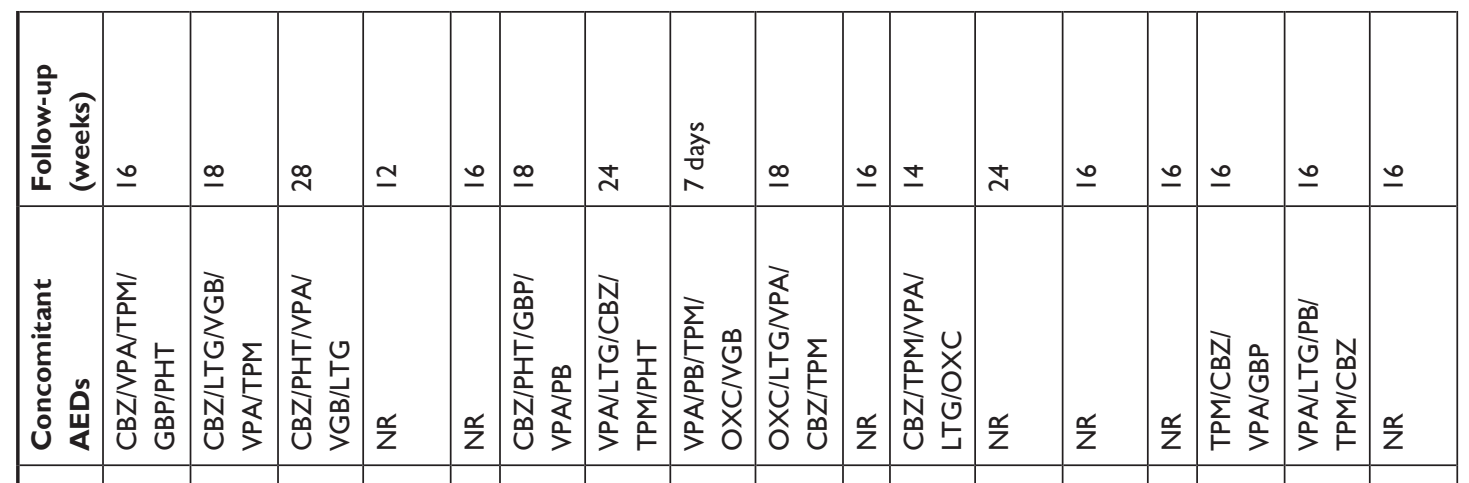

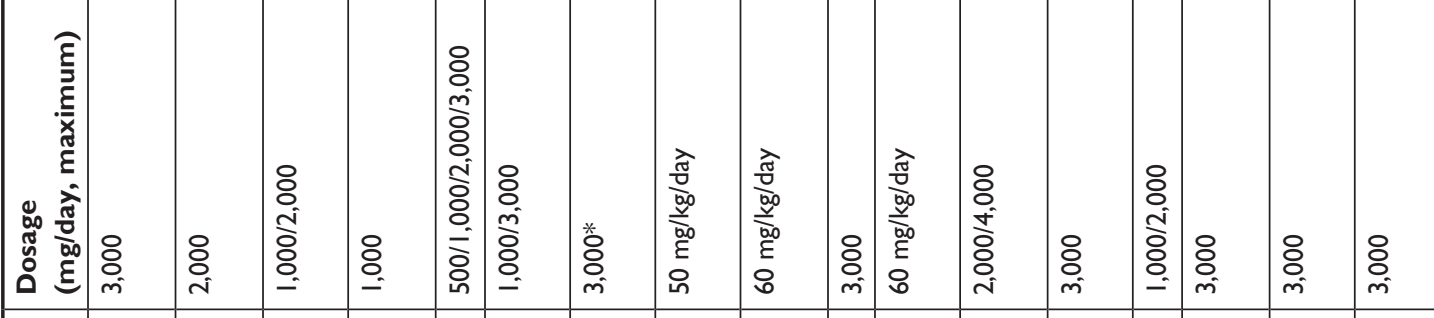

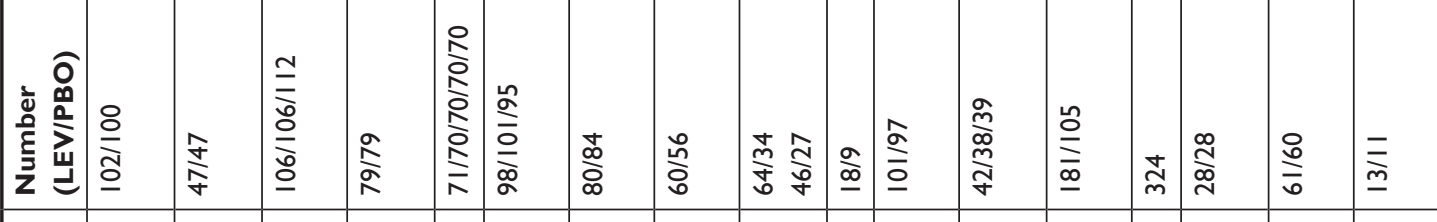

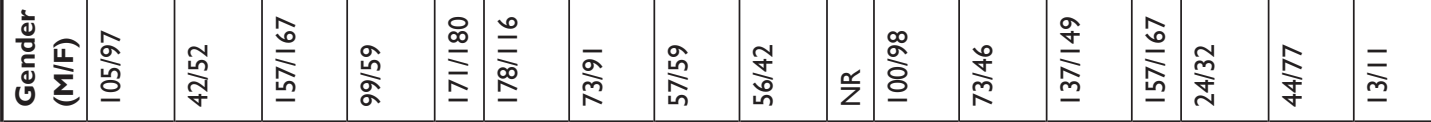

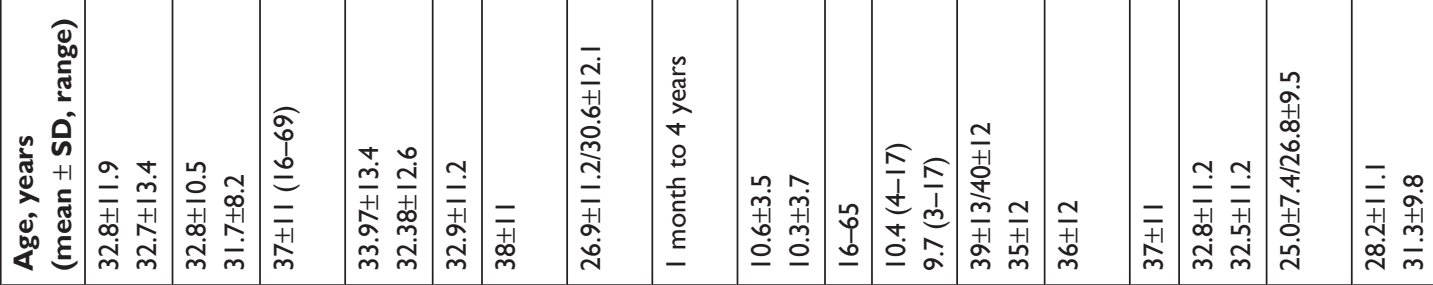

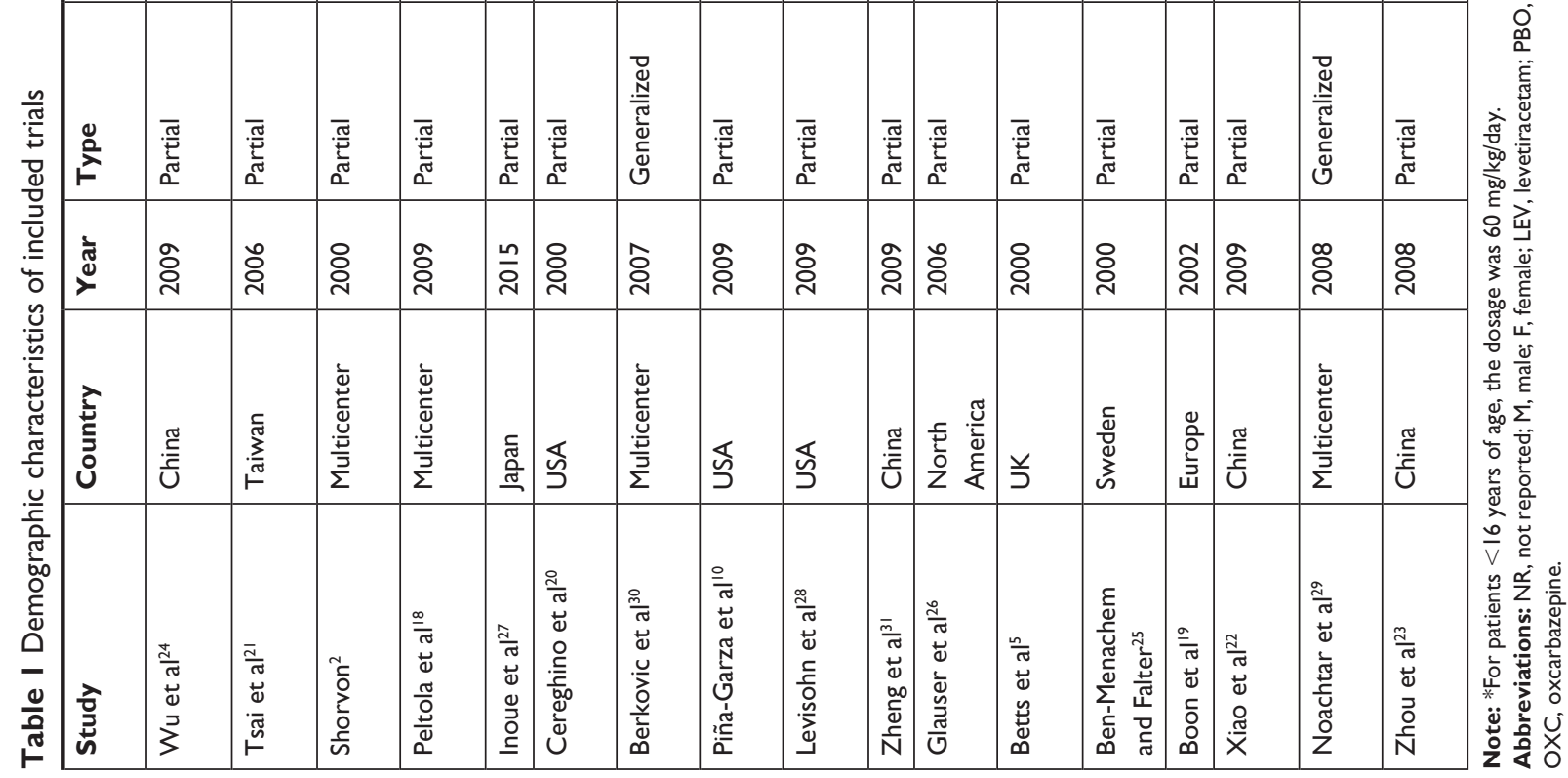




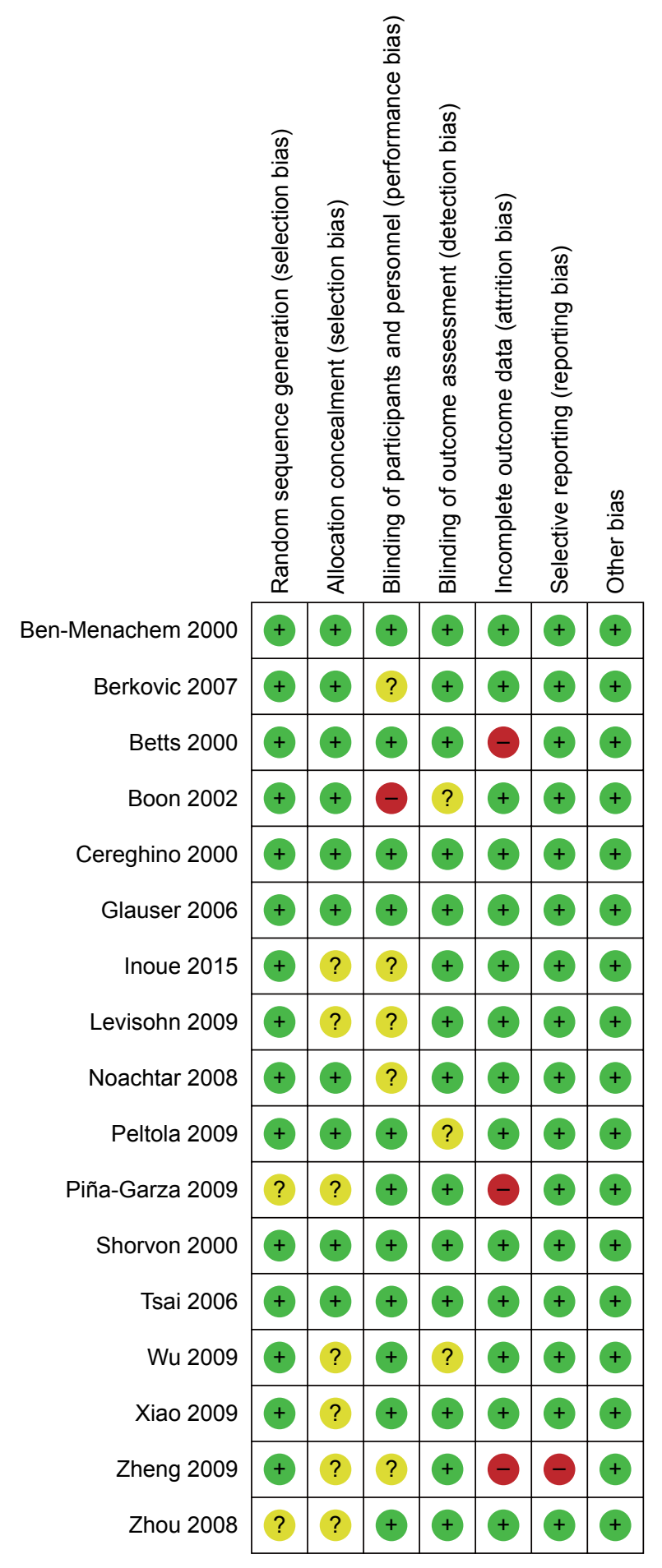

Figure 2 Risk of bias summary.

Notes: + , low; - , high; ?, unclear.

and $\mathrm{RR}=4.52,95 \%$ CI 2.09-9.77, respectively). For all of the four dosages, levetiracetam behaved substantially better than placebo $(P<0.05)$. However, on the other hand, at a dose of $4,000 \mathrm{mg} /$ day, a RR value of 2.05 (95\% CI 0.19-21.71) suggested that the efficacy was not substantial $(P=0.55)$. Subgroup analysis showed that there was no statistically significant difference between groups of age, with $R R=4.14$ for adulthood ( $95 \%$ CI 2.65-6.48) and RR $=4.31$ for children (95\% CI 1.99-9.32). Heterogeneity test suggested that there was no significant difference $(P=0.93)$ across trials. Analysis according to epilepsy type suggested that compared to refractory generalized epilepsy, refractory partial-onset seizures had a better seizure freedom rate $(\mathrm{RR}=3.11 \mathrm{vs} R \mathrm{RR}=4.44)$; however, the difference was not significant $(P=0.5)$. Figure 4 shows the details of seizure freedom from baseline compared to placebo.

\section{$75 \%$ reduction from baseline}

Besides responder and seizure freedom rates, eight trials reported $>75 \%$ reduction from baseline, ${ }^{2,18-23,31}$ and all of them involved patients of adulthood, with dosage of 1,000, 2,000, and 3,000 mg/day. Overall pooled estimates showed that for $75 \%$ reduction from baseline, levetiracetam had a substantial advantage over placebo $(\mathrm{RR}=4.45,95 \%$ CI 3.16 $6.26, P<0.05)$. Subgroup analysis based on dosage showed that 2,000 and 3,000 mg had comparable efficacy, calculated RRs were 5.87 (95\% CI 3.15-10.94) and 5.33 (95\% CI 2.37-6.26), respectively. However, heterogeneity test in $3,000 \mathrm{mg}$ group showed higher inconsistency $\left(I^{2}=52.2 \%\right.$, $P=0.10)$ than $2,000 \mathrm{mg} /$ day group $\left(I^{2}=0.0 \%, P=0.67\right)$, but it did not reach statistical significance. At a dosage of $1,000 \mathrm{mg} /$ day, even though levetiracetam performed inferior to 2,000 and $3,000 \mathrm{mg} /$ day, it is still significantly better than placebo $(\mathrm{RR}=3.37,95 \% \mathrm{CI} 2.08-5.44, P<0.05)$. Details are presented in Figure 5.

\section{SAE and side effects leading to withdrawal}

Almost all studies reported SAEs and withdrawals induced by interventions. As for SAEs, regardless of age and dosage, pooled estimates of RR $=0.87(95 \%$ CI $0.67-1.11, P=0.37$ ) suggested that there was no statistically significant difference between levetiracetam and placebo, and heterogeneity test of $P=0.56$ showed there was no significant heterogeneity was observed across included trials. Our subgroup analysis suggested that there was no statistically significant difference among dosages excepted at 4,000 mg/day, in which RR $=0.21(95 \% \mathrm{CI} 0.03-1.68, P=0.14)$. Subgroup analysis based on age showed no statistically significant difference between children $(\mathrm{RR}=0.86,95 \% \mathrm{CI} 0.36-2.05)$ and adults $(\mathrm{RR}=0.89$, 95\% CI 0.66-1.15), with $P=0.95$. Analysis according to epilepsy type showed that for partial-onset, $\mathrm{RR}=0.90(95 \% \mathrm{CI}$ $0.68-1.17)$, and for generalized epilepsy, $\mathrm{RR}=0.72(95 \% \mathrm{CI}$ 0.24-2.19), and difference between them was not significant $(P=0.71)$. Details of SAEs are demonstrated in Figure 6. 


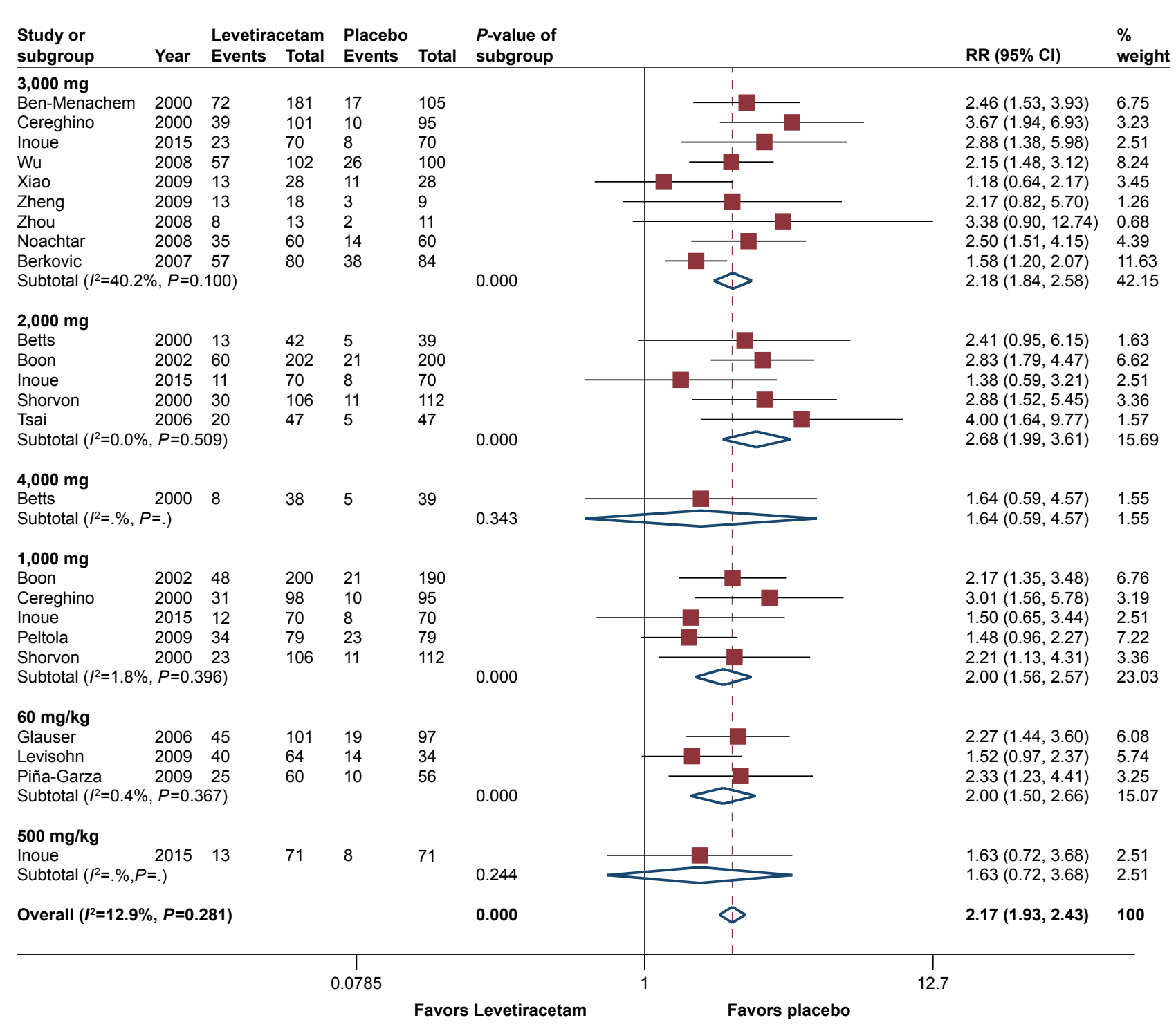

Figure 3 Forest plot of seizure frequency reduction $>50 \%$ from baseline, levetiracetam vs placebo. Abbreviation: $\mathrm{RR}$, risk ratio.

Regarding premature withdrawal, the situation was a little different. The pooled estimates of $\mathrm{RR}=1.34(95 \% \mathrm{CI}$ $1.05-1.71, P=0.02)$ indicated that discontinuation occurred in patients with levetiracetam and was substantially more common than placebo. Subgroup analysis showed dosages of $1,000,3,000$, and $60 \mathrm{mg} / \mathrm{kg} /$ day had comparable RRs, and there was no statistically significant difference between levetiracetam and placebo (Figure 7). However, for the dosage of 2,000 mg/day, calculated RR reached 1.92 (95\% CI $1.28-2.90$ ), and a $P$-value of 0.002 showed that withdrawal was significantly more common in patients treated with levetiracetam. Since $2,000 \mathrm{mg}$ /day was the significant factor affected the heterogeneity, it could also explain the discrepancy between children and adults, and the subgroup analysis according to age show that RR for children was 0.89 (95\%
CI 0.39-2.00, $P=0.77)$, and for adults, it was $1.39(95 \% \mathrm{CI}$ $1.07-1.81, P=0.01)$.

\section{Most common AEs}

Eleven AEs were reported by more than four studies, as demonstrated in Table 2. The most common side effect was somnolence, reported by 13 studies, including all the three trials related to children; $\mathrm{RR}=1.67$ (95\% CI 1.37-2.04) and $P<0.05$ suggested that the occurrence of this side effect was significantly higher in patients treated with levetiracetam. Subgroup analysis based on dosage showed that incidences in dosages of $1,000,2,000$, and $60 \mathrm{mg} / \mathrm{kg} /$ day were significantly more common in levetiracetam $(P<0.05)$. With regard to age, the analysis suggested that there was no statistically significant difference $(P=0.31)$ between children and adults 


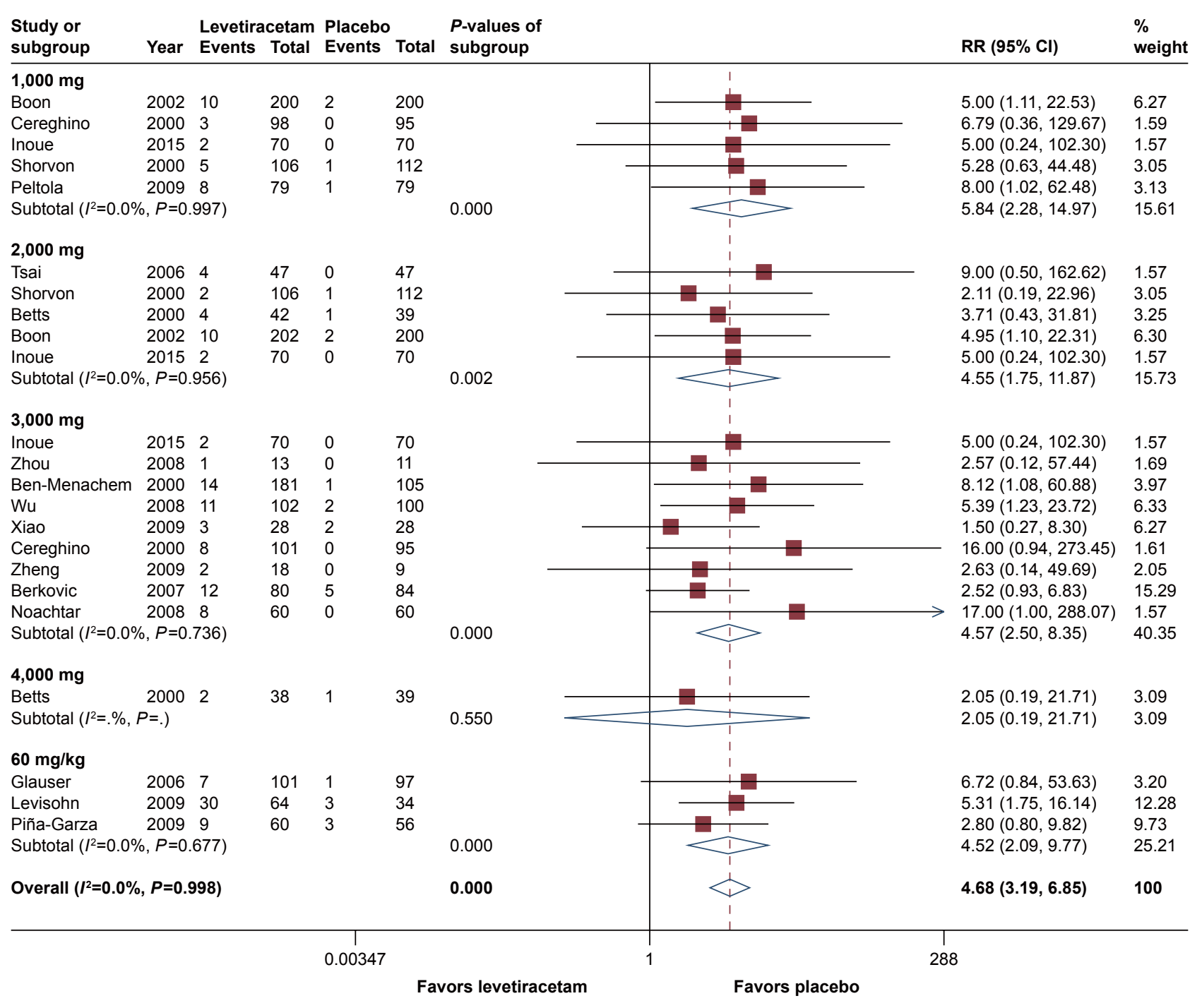

Figure 4 Forest plot of seizure freedom from baseline, levetiracetam vs placebo. Abbreviation: RR, risk ratio.

for this AE, even though children had a higher occurrence of $\mathrm{AE}$ than adults $(\mathrm{RR}=2.11 \mathrm{vs} R \mathrm{R}=1.54)$. Asthenia (fatigue) was also more frequent in patients with levetiracetam, and calculated $\mathrm{RR}=1.38$ (95\% CI 1.05-1.81, $P=0.02)$ suggested that the statistical difference between levetiracetam and placebo was significant. Subgroup analysis according to dosage suggested that $2,000 \mathrm{mg} /$ day was the most effective dose ( $R R=1.80)$; however, the occurrence of AE in levetiracetam group was not significantly higher than in placebo group $(P=0.05)$. Analysis based on age showed that this AE was more common in children $(\mathrm{RR}=1.74)$ than in adulthood $(\mathrm{RR}=1.41)$, but the differences between them did not reach statistical significance $(P=0.05)$. Another side effect that was widely reported was dizziness ( $\mathrm{RR}=1.50,95 \% \mathrm{CI} 1.13-2.00$, $P<0.05)$. Subgroup analysis suggested that dosage of 1,000 and $2,000 \mathrm{mg}$ /day had the highest occurrence $(\mathrm{RR}=1.72$ and 1.66, respectively); however, none of them reached statistically significant difference $(P=0.09$ and $P=0.10$, respectively) compared to placebo. With respect to infection, pooled estimates of RR was 1.56 (95\% CI 1.16-2.10, $P<0.05)$ which suggested that there was significant difference between levetiracetam and placebo, and the results from subgroup analysis showed that this side effect was more common for $1,000 \mathrm{mg} / \mathrm{day}(\mathrm{RR}=1.94, P<0.05)$ and $3,000 \mathrm{mg} /$ day $(\mathrm{RR}=2.05, P<0.05)$. Nasopharyngitis was also a widely reported $\mathrm{AE}$, by nine trials, and $\mathrm{RR}$ values through dosages ranged from 1.07 (2,000 $\mathrm{mg} /$ day) to $1.62(3,000 \mathrm{mg} /$ day $)$. Though there was no single dosage substantially higher than placebo, pooled estimates of $\mathrm{RR}=1.37$ (95\% CI 1.07-1.77, $P<0.05)$ suggested that occurrence of AE in levetiracetam group was significantly more common. Another AE of nausea was described by seven trials; nevertheless, pooled 


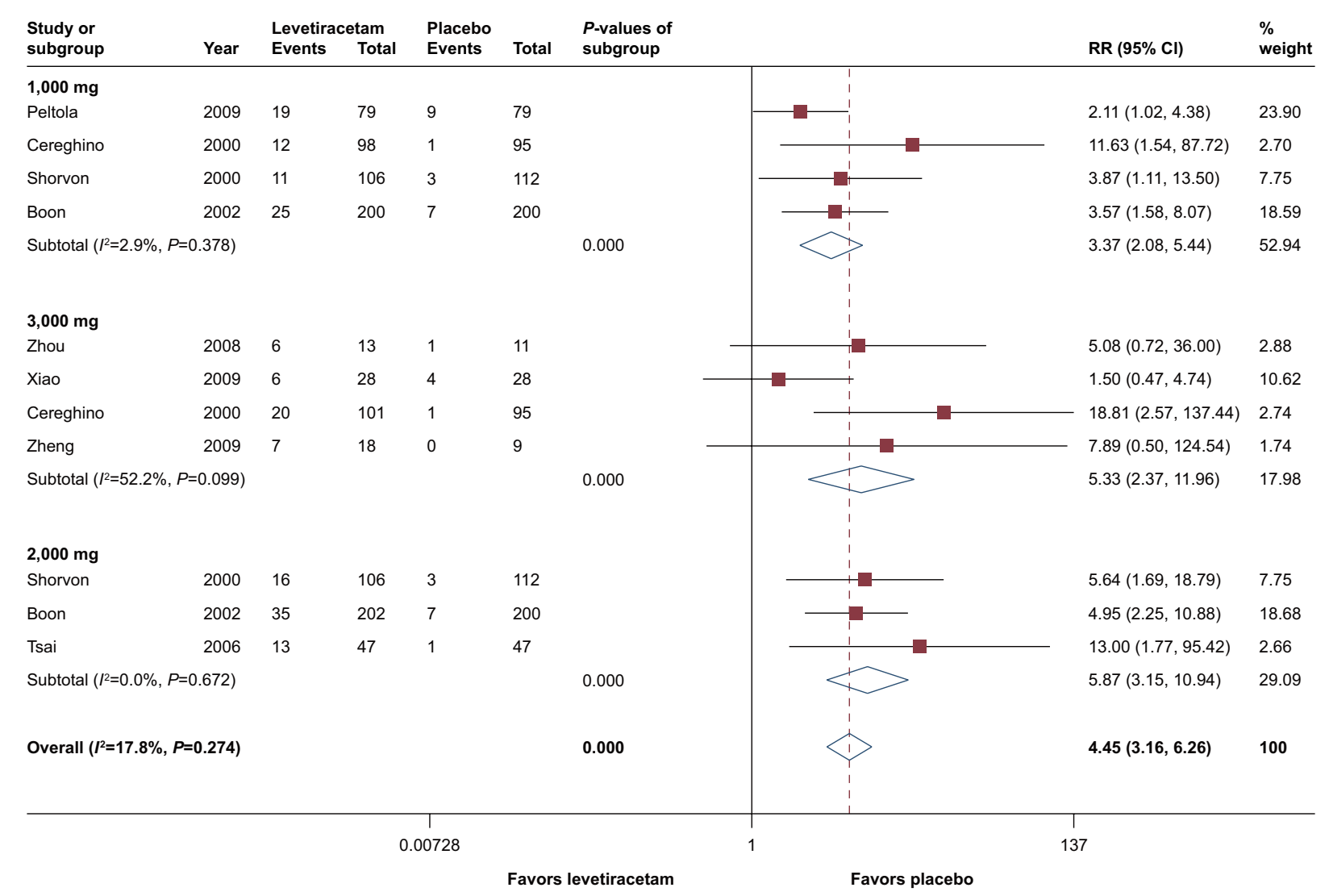

Figure 5 Forest plot of seizure frequency reduction $>75 \%$ from baseline, levetiracetam vs placebo. Abbreviation: $\mathrm{RR}$, risk ratio.

estimates of $\mathrm{RR}=1.09(95 \% \mathrm{CI} 0.72-1.63, P=0.7)$ suggested that there was no significant difference between levetiracetam and placebo.

\section{QoL}

Apart from efficacy and safety profile, four trials used the 31-item QoL in epilepsy questionnaire ${ }^{34}$ to evaluate the improvement of the QoL. ${ }^{20,23,29,30}$ Cereghino et al found that for the overall health-related QoL, there was no significant improvement; however, concerning three of seven items of seizure worry, cognitive functioning, and overall QoL, the effect was obvious. ${ }^{20}$ Berkovic et al reported in terms of total score; $38.3 \%$ of patients treated with levetiracetam had obvious improvement in overall QoL since the start of the study, by contrast, only $28.6 \%$ of patients with placebo showed improvement. ${ }^{30}$ In the trial of Noachtar et al, except for the social functioning, all of the other subscale scores were higher in the levetiracetam group than in the placebo group. ${ }^{29}$ Zhou et al also reported that patients benefited from levetiracetam with regard to QoL according to their study. ${ }^{23}$ Levisohn et al explored the cognitive effect by using the Leiter International Performance Scale-revised attention and memory (Leiter-R
AM), ${ }^{35}$ Wide Range Assessment of Memory and Learning (second edition, WRAML-2), ${ }^{36}$ and neither Leiter-R AM nor WRAML-2 showed statistically significant differences between the levetiracetam and placebo groups in changes from baseline to the end of the evaluation period in any of the index scores. ${ }^{28}$

\section{Publication bias}

Publication bias evaluation revealed that there was no potential bias across included studies, with Egger's test of $P=0.81$ and Begg's test of $P=0.6$.

\section{Discussion}

In this meta-analysis, we explored the efficacy, tolerability, and safety profile of levetiracetam based on 17 RCTs. Pooled estimates suggested that levetiracetam had a favorable efficacy for $50 \%, 75 \%$, and $100 \%$ seizure reduction from baseline. For 50\% reduction from baseline, dosages of $60 \mathrm{mg} / \mathrm{kg} /$ day, 1,000, 2,000, and 3,000 mg/day performed substantially better than placebo; furthermore, the difference was statistically significant. Four trials reported responder rate among levetiracetam group to be substantially higher at 


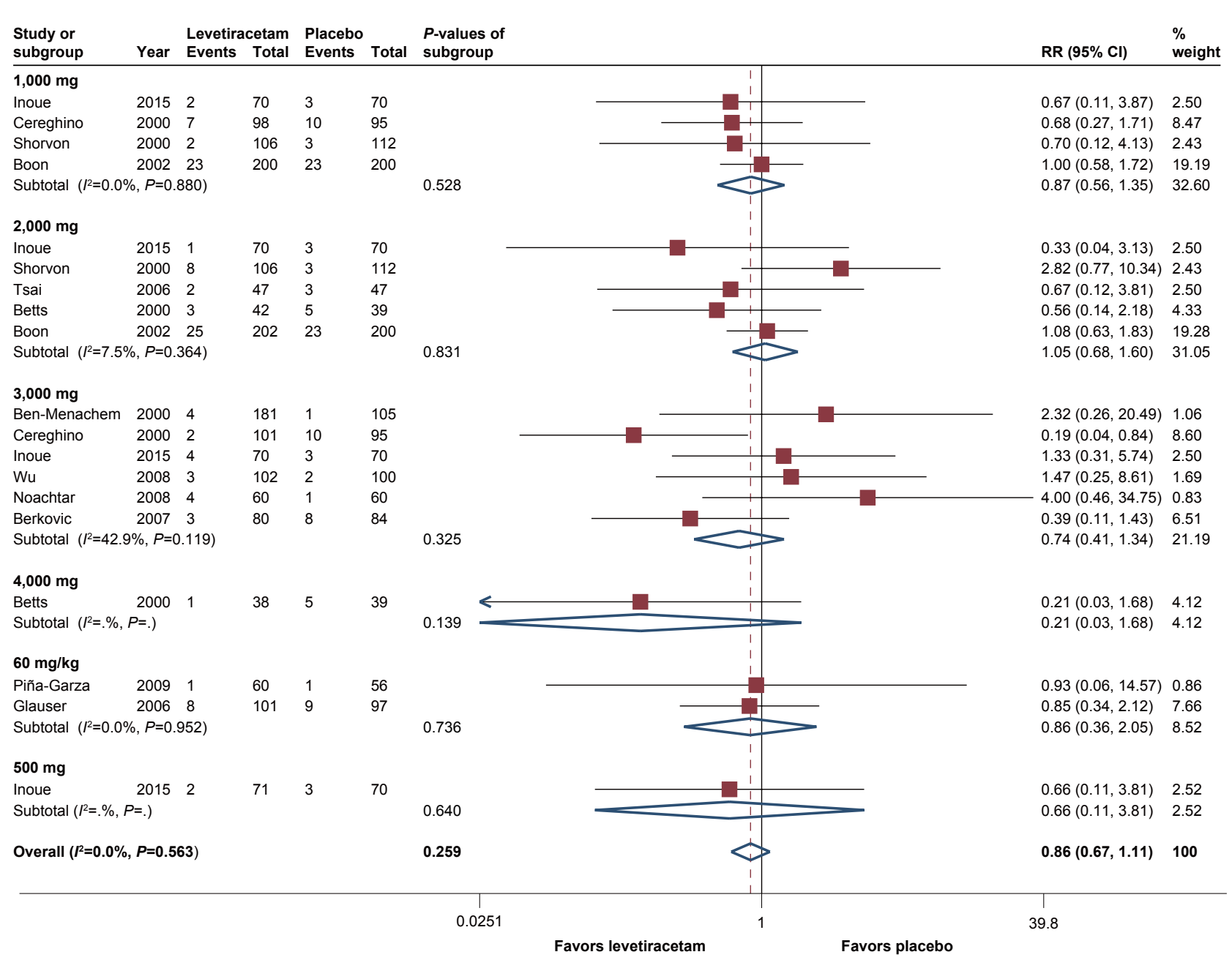

Figure 6 Forest plot of serious adverse events, levetiracetam vs placebo.

Abbreviation: RR, risk ratio.

$1,000 \mathrm{mg} / \mathrm{day},{ }^{2,18-20}$ while only one trial reported no statistically significant difference when compared to placebo. ${ }^{27}$ As for dosage of 3,000 mg/day, more than half RCTs reported significant improvement in patients treated with levetiracetam, ${ }^{20,24,25,27}$ whereas only two trials observed no significant difference between levetiracetam and placebo. ${ }^{22,31}$ Regarding efficacy among children, two of three trials described favorable responder rate at a dose of $60 \mathrm{mg} / \mathrm{kg} / \mathrm{day}$, which was equivalent to $3,000 \mathrm{mg} /$ day for adults. ${ }^{10,26}$ According to our analysis, it seemed $1,000 \mathrm{mg}$ /day was the optimal dosage for responder rate in most RCTs. In trial conducted by Boon et al, however, patients treated with 2,000 mg/day had significantly greater responder rate than those treated with $1,000 \mathrm{mg} /$ day $(P=0.018) .{ }^{19}$ For seizure freedom rate, patients treated with levetiracetam at $60 \mathrm{mg} / \mathrm{kg} / \mathrm{day}, 1,000$, 2,000, and 3,000 mg/day performed significantly better than with placebo, and there were three of six trials at $3,000 \mathrm{mg} /$ day $^{20,24,25}$ and one of three trials ${ }^{28}$ involving children observed that levetiracetam had significant greater seizure freedom rate.

As for the adverse profile, it seemed that somnolence, asthenia, dizziness, infection, nasopharyngitis, anxiety, and irritability were more common in patients treated with levetiracetam and significantly higher than patients with placebo. However, according to the description of studies, most of these AEs were mild or moderate and did not affect the treatment. Regarding the other six side effects reported by more than three trials of abdominal pain, accident injury, headache, flu syndrome, rash, and diarrhea, results from our analysis suggested that they were more common among patients with placebo than levetiracetam. In most studies, SAE was any AE that was fatal, life-threatening, or permanently or severely disabling or incapacitating, which resulted in prolonged hospitalization. SAEs were not substantially higher in patients treated with levetiracetam, in fact it was even lower $(\mathrm{RR}=0.87)$, and subgroup analysis suggested 


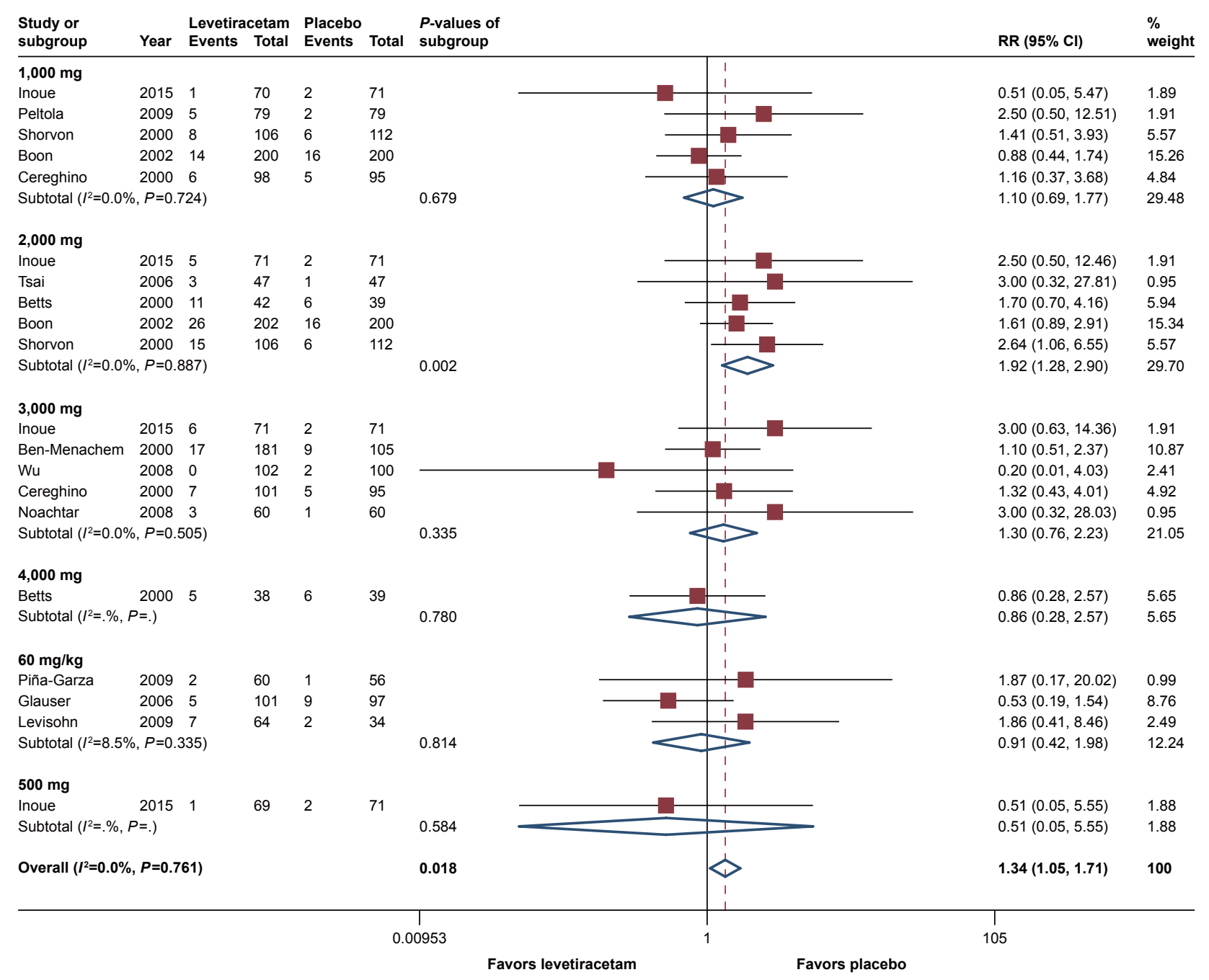

Figure 7 Forest plot of premature discontinuations, levetiracetam vs placebo.

Abbreviation: RR, risk ratio.

Table 2 Most common adverse events reported among included RCTs

\begin{tabular}{|c|c|c|c|c|c|c|}
\hline \multirow[t]{2}{*}{ System } & \multirow[t]{2}{*}{ Adverse event } & \multicolumn{2}{|l|}{ Events } & \multirow[t]{2}{*}{$\mathbf{R R}$} & \multirow[t]{2}{*}{$95 \% \mathrm{Cl}$} & \multirow[t]{2}{*}{$P$-value } \\
\hline & & Levetiracetam & Placebo & & & \\
\hline \multirow[t]{2}{*}{ Behavioral } & Anxiety & 13 & 1 & 5.79 & $1.33-25.13$ & 0.019 \\
\hline & Irritability & 17 & 2 & 6.09 & $1.80-20.64$ & 0.004 \\
\hline \multirow[t]{3}{*}{ Nervous } & Dizziness & 110 & 70 & 1.50 & $1.13-2.00$ & 0.005 \\
\hline & Headache & 137 & 149 & 0.85 & $0.69-1.06$ & 0.142 \\
\hline & Somnolence & 228 & 130 & 1.67 & I.37-2.04 & 0.000 \\
\hline \multirow[t]{2}{*}{ Gastrointestinal } & Diarrhea & 31 & 42 & 0.73 & $0.47-1.13$ & 0.159 \\
\hline & Nausea & 47 & 40 & 1.09 & $0.72-1.63$ & 0.695 \\
\hline \multirow[t]{5}{*}{ Others } & Flu syndrome & 31 & 39 & 0.80 & $0.50-1.21$ & 0.332 \\
\hline & Abdominal pain & 29 & 37 & 0.68 & $0.42-6.5 \mathrm{I}$ & 0.119 \\
\hline & Infection & 103 & 57 & 1.56 & $1.16-2.10$ & 0.004 \\
\hline & Accident injury & 77 & 100 & 0.74 & $0.56-0.96$ & 0.026 \\
\hline & Asthenia & 123 & 79 & 1.38 & $1.05-1.8 \mid$ & 0.02 \\
\hline Respiratory & Nasopharyngitis & 130 & 90 & 1.37 & I.07-1.77 & 0.013 \\
\hline Skin & Rash & 6 & 5 & 0.89 & $0.29-2.7 \mid$ & $0.84 I$ \\
\hline
\end{tabular}

Abbreviations: RR, risk ratio; RCT, randomized controlled trial. 
that the results were comparable through different dosages. Withdrawal induced by AEs was significantly higher in levetiracetam $(\mathrm{RR}=1.92, P<0.05)$, and subgroup analysis showed that except $2,000 \mathrm{mg} / \mathrm{day}$, for all of the other dosages, there was no statistically significant difference between levetiracetam and placebo. Some studies reported that compared to adults, children are prone to suffer from behavioral side effects such as aggression hostility and nervousness; ${ }^{11,32,33}$ however, because only two trials involved children (the other involved children $<4$ years, and lasted a period of 7 days; it was difficult to observe behavior-related side effects), we did not perform comparison between children and adults.

Regarding QoL, different measurements used across studies made it difficult to combine the data and to perform a meta-analysis. However, according to studies, it seemed that levetiracetam has some positive effects on QoL, but it is difficult to be sure of the real-life impact of these changes; thus, these conclusions remain to be validated in future.

Two meta-analyses on levetiracetam for refractory partialonset seizures were published earlier. One by Mbizvo et al included $11 \mathrm{RCTs},{ }^{32}$ in which comprised nine for adults and two for children and subgroup analyses were performed based on dosage. The difference between the present meta-analysis and theirs was that we analyzed the $75 \%$ and $100 \%$ reduction from baseline, after all, the goal of treatment for epilepsy is to achieve seizure freedom. Another difference was that other than the most common side effects and premature discontinuations that were reported, we analyzed SAEs. Besides, our meta-analysis included more trials than previous studies. In summary, our analyses revealed that levetiracetam was an effective anti-epileptic drug, and significantly superior to placebo regarding responder rate at 1000,2000 , and $3000 \mathrm{mg}$ /day for adults and $60 \mathrm{mg} /$ day for children, this was consistent with two earlier meta-analyses. Mbizvo et al found that doses of 2,000 and 4,000 mg/day levetiracetam had higher withdrawal rates, ${ }^{32}$ and our analysis suggested that at 2,000 $\mathrm{mg} / \mathrm{day}$, levetiracetam had statistically significant higher dropout rate than placebo. Another meta-analysis by Costa et al involved levetiracetam for the treatment of refractory partial-onset seizures, ${ }^{37}$ which primarily concentrated on comparison among several AEDs, and not only involved levetiracetam. Moreover, they did not provide subgroup analyses as well as detailed description regarding adverse events.

\section{Limitations}

Several limitations existed in the current meta-analysis. First, there were only three trials that involved children and one of them had a study period of only 7 days; hence, the results for children should be regarded with caution. Second, for the treatment of refractory generalized epilepsy, only two trials were included in this meta-analysis, and the results of analyses and comparison were susceptible to one of them. Third, several trials reported detailed efficacy for subtypes, but owing to insufficient data, it was difficult to perform analysis or comparison. Finally, all the included trials were placebo-controlled, thus our meta-analysis lacked comparison with other AEDs.

\section{Conclusion}

In summary, findings from the current meta-analysis suggested that levetiracetam at 1,000-3,000 mg/day (for children $60 \mathrm{mg} / \mathrm{kg} /$ day) is an effective AED for patients with refractory partial or generalized epilepsy, even in very young children. Moreover, levetiracetam has a favorable safety profile, and most of the AEs are mild or moderate. However, it seems that levetiracetam has a limited improvement in patients' QoL.

\section{Disclosure}

The authors report no conflicts of interest in this work.

\section{References}

1. Forsgren L, Beghi E, Oun A, Sillanpää M. The epidemiology of epilepsy in Europe - a systematic review. Eur J Neurol. 2005;12(4):245-253. doi:10.1111/j.1468-1331.2004.00992.x

2. Shorvon SD. The epidemiology and treatment of chronic and refractory epilepsy. Epilepsia. 1996;37(Suppl 2):S1-S3. doi:10.1111/j.1528-1157. 1996.tb06027.x

3. Mac TL, Tran D-S, Quet F, Odermatt P, Preux P-M, Tan CT. Epidemiology, aetiology, and clinical management of epilepsy in Asia: a systematic review. Lancet Neurol. 2007;6(6):533-543. doi:10.1016/ S1474-4422(07)70127-8

4. Kwan P, Brodie MJ. Early identification of refractory epilepsy. N Engl J Med. 2000;342(5):314-319. doi:10.1056/NEJM200002033420503

5. Betts T, Waegemans T, Crawford P. A multicentre, double-blind, randomized, parallel group study to evaluate the tolerability and efficacy of two oral doses of levetiracetam, 2,000 mg daily and 4,000 mg daily, without titration in patients with refractory epilepsy. Seizure. 2000; 9(2):80-87. doi:10.1053/seiz.2000.0380

6. Lynch BA, Lambeng N, Nocka K, et al. The synaptic vesicle protein SV2A is the binding site for the antiepileptic drug levetiracetam. Proc Natl Acad Sci U S A. 2004;101(26):9861-9866. doi:10.1073/pnas. 0308208101

7. De Smedt T, Raedt R, Vonck K, Boon P. Levetiracetam: part II, the clinical profile of a novel anticonvulsant drug. CNS Drug Rev. 2007; 13(1):57-78. doi:10.1111/j.1527-3458.2007.00005.x

8. Otoul C, Smedt HD, Stockis A. Lack of pharmacokinetic interaction of levetiracetam on carbamazepine, valproic acid, topiramate, and lamotrigine in children with epilepsy. Epilepsia. 2007;48(11): 2111-2115. doi:10.1111/j.1528-1167.2007.01201.x

9. Pellock JM, Glauser TA, Bebin EM, et al. Pharmacokinetic study of levetiracetam in children. Epilepsia. 2001;42(12):1574-1579. doi:10.1046/j.1528-1157.2001.41300.x

10. Piña-Garza JE, Nordli DR Jr, Rating D, Yang H, Schiemann-Delgado J, Duncan B. Adjunctive levetiracetam in infants and young children with refractory partial-onset seizures. Epilepsia. 2009;50(5):1141-1149. doi:10.1111/j.1528-1167.2008.01981.x 
11. Egunsola O, Choonara I, Sammons HM, Thippeswamy T. Safety of levetiracetam in paediatrics: a systematic review. PLoS One. 2016; 11(3):e0149686. doi:10.1371/journal.pone.0149686

12. Liberati A, Altman DG, Tetzlaff J, et al. The PRISMA statement for reporting systematic reviews and meta-analyses of studies that evaluate healthcare interventions: explanation and elaboration. Epidemiol Biostat Public Health. 2009;6(4):e1-e34.

13. DerSimonian R, Laird N. Meta-analysis in clinical trials. Control Clin Trials. 1986;7(3):177-188.

14. Mantel N, Haenszel W. Statistical aspects of the analysis of data from retrospective studies of disease. J Natl Cancer Inst. 1959;22(4): 719-748.

15. Higgins JP, Green S, editors. Cochrane Handbook for Systematic Reviews of Interventions. Chichester, UK: John Wiley \& Sons, Ltd; 2008.

16. Begg CB, Mazumdar M. Operating characteristics of a rank correlation test for publication bias. Biometrics. 1994;50(4):1088. doi:10.2307/ 2533446

17. Egger M, Smith GD, Schneider M, Minder C. Bias in meta-analysis detected by a simple, graphical test. BMJ. 1997;315(7109):629-634. doi:10.1136/bmj.315.7109.629

18. Peltola J, Coetzee C, Jiménez F, et al. Once-daily extended-release levetiracetam as adjunctive treatment of partial-onset seizures in patients with epilepsy: a double-blind, randomized, placebo-controlled trial Epilepsia. 2009;50(3):406-414. doi:10.1111/j.1528-1167.2008.01817.x

19. Boon P, Chauvel P, Pohlmann-Eden B, Otoul C, Wroe S. Dose-response effect of levetiracetam 1,000 and 2,000 mg/day in partial epilepsy. Epilepsy Res. 2002;48(1-2):77-89. doi:10.1016/S0920-1211(01) 00323-0

20. Cereghino JJ, Biton V, Aboukhalil B, Dreifuss F, Gauer LJ, Leppik I. Levetiracetam for partial seizures: results of a double-blind, randomized clinical trial. Neurology. 2000;55(2):236-242.

21. Tsai JJ, Yen DJ, Hsih MS, et al. Efficacy and safety of levetiracetam (up to 2,000 mg/day) in Taiwanese patients with refractory partial seizures: a multicenter, randomized, double-blind, placebo-controlled study. Epilepsia. 2006;47(1):72-81.

22. Xiao Z, Li J-M, Wang X-F, et al. Efficacy and safety of levetiracetam (3,000 $\mathrm{mg} /$ Day) as an adjunctive therapy in Chinese patients with refractory partial seizures. Eur Neurol. 2009;61(4):233-239. doi:10.1159/ 000197109

23. Zhou B, Zhang Q, Tian L, Xiao J, Stefan H, Zhou D. Effects of levetiracetam as an add-on therapy on cognitive function and quality of life in patients with refractory partial seizures. Epilepsy Behav. 2008;12(2):305-310. doi:10.1016/j.yebeh.2007.10.003

24. Wu X, Hong Z, Wu X, et al. Multicenter double-blind, randomized, placebo-controlled trial of levetiracetam as add-on therapy in Chinese patients with refractory partial-onset seizures. Epilepsia. 2009;50(3):398. doi:10.1111/j.1528-1167.2008.01729.x
25. Ben-Menachem E, Falter U. Efficacy and tolerability of levetiracetam $3,000 \mathrm{mg} / \mathrm{d}$ in patients with refractory partial seizures: a multicenter, double-blind, responder-selected study evaluating monotherapy. Epilepsia. 2000;41(10):1276-1283.

26. Glauser TA, Ayala R, Elterman RD, et al. Double-blind placebocontrolled trial of adjunctive levetiracetam in pediatric partial seizures. Neurology. 2006;66(11):1654-1660.

27. Inoue $\mathrm{Y}$, Yagi K, Ikeda A, et al. Efficacy and tolerability of levetiracetam as adjunctive therapy in Japanese patients with uncontrolled partial-onset seizures. Psychiatry Clin Neurosci. 2015;69(10):640-648. doi:10.1111/pcn.12300

28. Levisohn PM, Mintz M, Hunter SJ, Yang H, Jones J, N01103 Levetiracetam Study Group. Neurocognitive effects of adjunctive levetiracetam in children with partial-onset seizures: a randomized, double-blind, placebo-controlled, noninferiority trial. Epilepsia. 2009;50(11): 2377-2389. doi:10.1111/j.1528-1167.2009.02197.x

29. Noachtar S, Andermann E, Meyvisch P, Andermann F, Gough WB, Schiemann-Delgado J. Levetiracetam for the treatment of idiopathic generalized epilepsy with myoclonic seizures. Neurology. 2008;70(8) 607. doi:10.1212/01.wnl.0000297512.18364.40

30. Berkovic SF, Knowlton RC, Leroy RF, Schiemann J, Falter U. Placebocontrolled study of levetiracetam in idiopathic generalized epilepsy. Neurology. 2007;69(18):1751-1760.

31. Zheng X, Wu S, Xia M, Li Q. Study on the therapeutic effect of levetiracetam as an additive therapy for refractory partial epilepsy and the relativity between levetiracetam and multidrug resistance gene: a randomised double-blind placebo-controlled trial. Chin J Contemp Neurol Neurosurg. 2009;9(02):173-177.

32. Mbizvo GK, Dixon P, Hutton JL, Marson AG. Levetiracetam add-on for drug-resistant focal epilepsy: an updated Cochrane Review. Cochrane Database Syst Rev. 2012;(9):CD001901. doi:10.1002/14651858. CD001901.pub2

33. Halma E, de Louw AJA, Klinkenberg S, Aldenkamp AP, IJff DM, Majoie M. Behavioral side-effects of levetiracetam in children with epilepsy: a systematic review. Seizure. 2014;23(9):685-691. doi:10.1016/j. seizure.2014.06.004

34. Cramer JA, Perrine K, Devinsky O, Bryant-Comstock L, Meador K, Hermann B. Development and cross-cultural translations of a 31-item quality of life in epilepsy inventory. Epilepsia. 1998;39(1):81-88.

35. Farmer C. Leiter International Performance Scale-Revised (Leiter-R). New York: Springer New York; 2013.

36. Dumont R, Willis JO, Veizel K, Zibulsky J. Wide Range Assessment of Memory and Learning. 2nd ed. Hoboken: John Wiley \& Sons, Inc.; 2014.

37. Costa J, Fareleira F, Ascenção R, Borges M, Sampaio C, Vaz-Carneiro A. Clinical comparability of the new antiepileptic drugs in refractory partial epilepsy: a systematic review and meta-analysis. Epilepsia. 2011;52(7):1280-1291. doi:10.1111/j.1528-1167.2011.03047.x
Neuropsychiatric Disease and Treatment

\section{Publish your work in this journal}

Neuropsychiatric Disease and Treatment is an international, peerreviewed journal of clinical therapeutics and pharmacology focusing on concise rapid reporting of clinical or pre-clinical studies on a range of neuropsychiatric and neurological disorders. This journa is indexed on PubMed Central, the 'PsycINFO' database and CAS,

\section{Dovepress}

and is the official journal of The International Neuropsychiatric Association (INA). The manuscript management system is completely online and includes a very quick and fair peer-review system, which is all easy to use. Visit http://www.dovepress.com/testimonials.php to read real quotes from published authors. 